\title{
Suicidal ideation and attempt among people living with HIV/AIDS in selected public hospitals: Central Ethiopia
}

\author{
Kefyalew Dagne Gizachew ${ }^{1,2^{*}}$ (D) Yigrem Ali Chekol $^{3}$, Elyas Admasu Basha' ${ }^{1}$, Shiferaw Abeway Mamuye ${ }^{4}$ \\ and Abate Dargie Wubetu ${ }^{1}$
}

\begin{abstract}
Background: Suicide is the act of intentionally causing one's own death. HIV/AIDS continues to be associated with an under-recognized risk for suicidal behavior. Suicidal behavior among people living with HIV/AIDS is not only a predictor of future attempted suicide and completed suicide, but it is also associated with poor quality of life and poor adherence with antiretroviral therapy.
\end{abstract}

Objective: The aim of this study was to assess the prevalence of suicidal ideation and attempt and associated factors among people living with HIV/AIDS in selected public hospitals of Amhara region, central Ethiopia.

Methods: Institutional based cross-sectional study design was employed. The study was conducted in four public hospitals in North Shewa Zone from May to December 2017. Study population comprised all HIV-infected individuals from Antiretroviral Therapy (ART) clinic. A total of 348 study subjects were recruited using systematic random sampling and 326 completed the interview. Suicidality module from Composite International Diagnostic Interview (CIDI) was modified to assess suicidal behavior. Crude and adjusted OR was analyzed using logistic regression and the level of significance of association was determined at $P$ value $<0.05$.

Result: A total of $326(93.7 \%)$ study subjects were interviewed. The magnitude of suicidal ideation and attempt was found to be $16 \%$ and $7.1 \%$, respectively. Low monthly income, living alone, suicidal thought before knowing seropositive status, family history of suicide, experiencing mild and moderate-to-severe depression and anxiety symptoms, being gossiped sometimes in the last 12 months of the study period due to HIV status and ever use of khat (a psychoactive substance) was statistically significant associated factor with suicidal ideation. And low monthly income, experiencing mild and moderate-to-severe depression and anxiety symptoms, being gossiped sometimes and often in the previous 12 months of the study period due to HIV status and using alcohol currently were significantly associated factors with suicidal attempt.

Conclusion: Suicidal ideation and attempt among people living with HIV/AIDS (PLWHA) in this study were higher than prevalence in the general population. This shows suicidal ideation and attempt is a mental health concern of PLWHA and it needs great attention in Ethiopia.

Keywords: Suicidal ideation, Suicidal attempt, HIV/AIDS, Prevalence, Ethiopia

*Correspondence: kdgc08@yahoo.com

${ }^{1}$ Department of Psychiatry, College of Health Sciences and Medicine, Debre Berhan University, P.O. Box 445, Debre Berhan, Ethiopia

Full list of author information is available at the end of the article

\section{Background}

Suicide is the act of intentionally causing one's own death or an intentional termination of one's own life, and it is often committed out of despair, the cause of which is frequently attributed to a mental disorder such 
as depression, bipolar disorder, schizophrenia, alcoholism, or drug abuse, and all these problems could be related with profound pain, hopelessness and despair that resulted in suicidal behavior $[1,2]$.

More than 800,000 people die by suicide annually, making it the 10th leading cause of death worldwide, and there are an estimated 10 to 20 million non-fatal attempted suicides every year [3, 4]. Developing and developed countries have parallel annual age standardized rates of suicide_11.2 and 12.7 per 100,000, respectively; however, $75 \%$ of suicide deaths globally is from developing countries [5].

Reports show that the rate of suicidality is higher in men than in women, with males three to four times more likely to kill themselves than females [4, 6], and suicidal attempts are more common in young people and females [3].

Studies from USA showed that, approximately $90 \%$ of completed suicides are associated with a mental disorder, and patterns are likely to be similar globally [3]. Factors related with suicide that are universal in both developed and developing world include youth or old age, low socioeconomic status, substance use, past history of suicide attempts, recent adverse life events, and access to methods to commit suicide [7].

Studies from sub-Saharan Africa (SSA) region show rates of suicide can be like those of developed countries and premature death from suicide has uncounted adverse consequences including: direct loss of life; loss of a breadwinner (parent or guardian); persistent psychological trauma for children, friends and relatives; and the loss of economic productivity for the nation at large [8].

Researchers have long known that human immunodeficiency virus (HIV) and AIDS (HIV/AIDS) is associated with an uncovered risk for suicidal behavior despite improvement in treatment and care that transformed HIV/AIDS into a treatable chronic illness [9]. Several factors predispose HIV/AIDS patients more likely to commit suicide including: they think that they will die earlier than they expected and worry that their deaths might be prolonged and imposes emotional and physical pain; and they may also be hopeless about the consequences of losing their jobs, their insurance, or their homes [10].

Suicidal behavior in HIV/AIDS is not only a predictor of future attempted suicide and completed suicide, but it is also associated with poor quality of life (QoL) and poor adherence with antiretroviral therapy [11, 12]. Existing studies report that important predictors for poor QoL among HIV-infected persons are: physical manifestations of the disease, antiretroviral therapy, psychological wellbeing, social support systems, coping strategies, spiritual well-being, and psychiatric comorbidities and these all could lead to suicidal behavior [13].
Reports shows that HIV has been associated with increased thoughts of suicidality, but estimates of the prevalence of lifetime suicidal ideation and attempt, and risks for new-onset suicide among HIV-infected individuals are not widely available in the era of modern combined antiretroviral treatment (cART) [14]. Findings also suggest that risk of suicidality is higher during early times (initial weeks) after positive test for HIV and then decrease as people infected with HIV start to adjust to their HIV status $[15,16]$.

Studies conducted before the introduction of HIV drugs_highly active antiretroviral therapy (HAART) showed an increased risk of completed suicide in patients with HIV/AIDS; that was 7 to 36 times greater than in the non-HIV-infected population $[17,18]$. Since the introduction of HAART, findings suggests that suicidality among HIV-infected individuals decreased significantly, but remain above the rate reported in the general population [19]; and it may be mediated more often by factors other than HIV/AIDS itself including: depressive symptoms, alcohol use disorder, or other substance use disorders [20].

Risk of suicidality among HIV-infected patients may be higher than in populations with other chronic medical illnesses, such as cancer [21]. Suicidal ideation, attempted suicide, and committed suicide occur at a higher rate among patients with HIV infection than in the general population and individuals with HIV/AIDS are subject to disease-specific stressors and to a greater number of general suicide risk factors [14, 22].

To compare rate of suicidality between HIV-infected individuals and other patients with medical, mental conditions or the general public, the following were mentioned as instances. Suicidal behavior among cohorts of severe mental illness patients in rural Ethiopia was reported as; cumulative risk of suicide attempt, $26.3 \%$ for major depression; 23.8\% for bipolar I disorder; $13.1 \%$ for schizophrenia [23]. Another study at University of Gondar Hospital Psychiatric Clinic patients estimated a $19.2 \%$ attempted suicide at least once after the onset of mental illness and $64.8 \%$ had suicidal ideation [24].

But reports on suicidal study in Ethiopia using the general population showed the lifetime suicide attempt of $3.2 \%$ at Butajira; and the prevalence of current suicidal ideation was $2.7 \%$, and lifetime prevalence of suicidal attempt was $0.9 \%$ at Addis Ababa in which hanging and poisoning were the commonest methods of attempting suicide $[25,26]$. A more recent comparative study at Northwest Ethiopia showed the prevalence of suicidal behavior in people with epilepsy to be $18.2 \%$, and in the community sample to be $9.8 \%$ [27].

Previous studies in Ethiopia reported different prevalence of suicidal behavior among people living with HIV/ 
AIDS (PLWHA), findings reported as follows. Prevalence of suicidal ideation and attempt among PLWHA were reported to be $22.5 \%$ and $13.9 \%$ at Zewditu Memorial Hospital, Addis Ababa [28]; 33.6\% and 20.1\%, at Debark Hospital, North Gondar [29]; and $24.3 \%$ and $12.6 \%$ at Hiwot Fana Specialized Hospital, Harar, respectively [30].

As per our search of data bases, reports from subSaharan African countries including Ethiopia are few on suicidality and HIV/AIDS, and screening suicidal behaviour is a highly recommended strategy to prevent mental health related deaths [31]. But the association between suicidality and HIV infection is attracting attention to date [32]. The rapidly growing literature on HIV/AIDS in Ethiopia has failed to examine the prevalence, associated factors, and its impacts of suicidality among people living with HIV/AIDS. It is therefore anticipated that this study findings will contribute to the development of local knowledge about suicidal behavior and HIV/AIDS and be used to scale-up the assessment of suicide risk in these patients involving a thorough exploration of these vulnerabilities.

\section{Objective}

The aim of this study was to assess prevalence and factors associated with suicidal ideation and attempt among people living with HIV/AIDS in selected public hospitals, in central Ethiopia.

\section{Methods}

\section{Study design, period, and area}

Institutional based cross-sectional study design was employed from May to December 2017. The study was conducted in selected public hospitals of North Shewa Zone, which provides ART and pre-ART HIV/AIDS treatment and services. North Shewa Zone is one of the 11 Zones in Amhara administrative regional state and the City is Debre Berhan town, located $695 \mathrm{~km}$ from Bahir-Dar, capital of the region and $130 \mathrm{~km}$ from Addis Ababa, capital of Ethiopia. There are seven public hospitals in North Shewa Zone, one referral hospital and six primary hospitals. During data collection period, only three primary hospitals and the referral hospital were giving comprehensive HIV care and treatment and all are included in the study. Debre Berhan Comprehensive Specialized Hospital is the only referral hospital not only in the town but also in that zonal administrative catchment area (North Shewa Zone) and provides services for people from some part of Afar Region and it is estimated it serves for more than two million people. According to North Shewa zonal health office report of 2017 for comprehensive pre-ART and ART services (HIV/AIDS care) in all health facilities, these selected hospitals provide for the total number of 3,406 HIV-positive adults receiving clinical care during the data collection period: Debre Berhan Comprehensive Specialized Hospital, 2038 (95 on pre-ART and 1943 on ART); Ataye Primary Hospital, 291 (41 on pre-ART and 198 on ART); Alem ketema Enat Hospital, 690 (50 on pre-ART and 640 on ART); Mehal Meda Hospital, 439 (23 on pre-ART and 640 on ART).

\section{Source population}

All HIV-infected patients receiving treatment of ART at ART clinics in public hospitals of North Shewa Zone in Amhara region, Ethiopia.

\section{Study population}

All HIV infected patients receiving treatment of ART at ART clinics in selected public hospitals of North Shewa Zone and who were available during the study period.

\section{Inclusion criteria}

The sample includes participants aged 18 years and above, tested HIV positive and currently receiving care and treatment for HIV/AIDS in all selected public hospitals providing ART services.

\section{Exclusion criteria}

Those with severe illness and unable to communicate for data collection.

\section{Sample size determination}

In this study, sample size was determined using single population proportion formula. Previous prevalence of suicidal ideation (34.7\%) in a study conducted in Benin City, Nigeria, was taken to obtain the maximum sample size at $95 \%$ certainty with a maximum discrepancy of $5 \%$ between the sample and the underlying population. For possible none response during the survey, the final sample size was increased by $10 \%$ and determined to be 348 .

\section{Sampling procedures}

Systematic random sampling technique was employed to recruit participants from each of the four sites. Proportional allocation was used among all public hospitals which has been providing HIV/AIDS care services. Sampling fractions was determined by dividing total study population who has monthly follow up during study period (pre-ART and ART clients) by the total sample size and participants were interviewed every 10th interval (see Additional file 1).

\section{Data collection instruments and operational definitions}

A semi-structured questionnaire was used to collect data on socio-demographic characteristics (age, sex, ethnicity, religion, education, occupation, and marital status). 
Past psychiatric history, suicidal history (suicidal attempts or expression of thoughts) before HIV infection, family history of suicide (attempted or completed suicide) and family history of known psychiatric illness was measured with participants' self-report. Productive work (employment status) was defined as any work without monetary benefit and constitutes household work, studying or other work without payment [33].

Suicidality module from Composite International Diagnostic Interview_CIDI [34] was modified for our study context to assess suicidal behavior among people living with HIV/AIDS. CIDI was adapted in to Amharic language and determined to be reliable, acceptable, and feasible in Ethiopian mental health studies [35]. Suicidal ideation was defined as if the respondent answers "Yes" for the question "have you ever seriously thought about committing suicide after you know your serostatus?" Suicidal attempt was defined as if the respondent answers "Yes" for the question "have you ever attempted suicide after you know your sero-status?".

Presence of co-morbid diseases were defined when subjects have at least one or more self-reported known chronic medical or physical diseases. A recent CD4 count, HIV/AIDS stage and duration since HIV status known were taken from respective formats and patients' chart.

Substance use was assessed using purposely specified substances from "The alcohol, smoking and substance involvement screening test, ASSIST" [36]. ASSIST was developed for use in different cultural context and psychometric properties were tested using data across countries (both developing and developed) and recommended to be reliable, valid and simple for administration [37]. Ever use of substance was defined as ever use of at least one of specified substances in life time; and current use of substance was defined as use of at least one of specified substances in the previous three months before data collection.

Presence of anxiety and depression together and independently were identified using an ultra-brief screening scale for anxiety and depression: the PHQ-4 (the FourItem Patient Health Questionnaire for Anxiety and Depression) [38]. PHQ-4 is a valid ultra-brief tool for detecting both anxiety and depressive disorders and it is shown to be excellent screening tool [38], and translated in to Amharic in this study. A cut point of $\geq 3$ on for PHQ-2 scale has a sensitivity of $83 \%$ and specificity of $90 \%$ for major depressive disorder [39]; and cut point of $\geq 3$ for GAD-2 scale has sensitivity of $88 \%$ for generalized anxiety disorder [40]. Combined anxiety and depression symptoms was defined positive from the total sum of PHQ-4 scores, and rated as normal (0-2), mild (3-5), moderate (6-8), and severe (38). Presence of anxiety symptoms alone was suggested by total score of $\geq 3$ for first 2 questions of PHQ-4 [38], and depressive symptoms suggested by total score of $\geq 3$ for last 2 questions of PHQ-4 [38].

Perceived social support was assessed using Oslo-3 item Social Support (OSS-3) scale to see the degree of social support and this scale is widely used in Ethiopia $[41,42]$. OSS-3 in this study was scored according to total points ranging from 3-14; "poor support" 3-8, "moderate support" 9-11, and "strong support" 12-14 [41].

FICA Tool for Spiritual Assessment which includes Faith or belief, Importance of spirituality, individual's spiritual Community, and interventions to Address spiritual needs was applied to evaluate the strength of spirituality, and FICA items were closely correlated with items from the quality of life (QoL) tools addressing spiritual component and this tool was feasible for clinical assessment of spirituality in previous studies [43]. Using FICA tool, a statement "Do you consider yourself spiritual or religious?"_ from "Faith, Belief, Meaning (F)" component was designed with "yes/no" option; and from "Importance and Influence (I)" component of FICA; "on a scale of 0 (not important) to 5 (very important), how would you rate the importance of faith/belief in your life?" was asked to subjects and mean score was considered as a cut off [43]. Experienced stigma was evaluated using two questions from "Illustrative questions by domain of HIV stigma and discrimination" for experienced stigma about gossip and exclusion from social gatherings or activities because of HIV status in the last 12 months [33].

Physical and sexual abuse was assed using Abuse Assessment Screen (AAS) with slight modification of timing, and AAS was shown to be a reliable and valid instrument for screening for abuse [44].

Current health status of PLWHA was assessed by asking participants to rate their current health status according to a five-category index: HIV-positive, with no symptoms, have symptoms, but have not had to change normal daily routines, have symptoms that have required to change parts of normal routines of daily activities (extra rest is not required during a normal day), because of symptoms, being in bed, or resting (less than half of waking hours), because of symptoms, being in bed, or resting (more than half of waking hours) [45].

\section{Data collectors and data quality control}

The principal investigator recruited four-degree holder nurses (one from each of the four study sites) for data collection. Data collectors was trained and oriented on how to use of the questionnaire, the ethical principles of confidentiality and data management prior to their involvement with data collection. The questionnaire was designed and modified appropriately. The questionnaire 
including all instruments used were translated to local language_Amharic (participants interviewed with Amharic version) to be understood by all participants and translated back to English. Training was given for data collectors. Pre-test was done on $5 \%$ of the sample size before the start of actual data collection to test simplicity and easy understandability of the questionnaire at a distinct primary health care facility other than selected public hospitals for this study, and based on the finding from the pretest, the questioner was revised accordingly and time needed for interview was estimated. The data collectors were supervised routinely by assigned supervisors and the completed questionnaires was checked daily by the principal investigators and assistant investigators for completeness and consistency.

\section{Data processing and analysis}

After data was checked for completeness and consistency, it was coded and entered in to Epi Data 3.1. Then, data was exported to SPSS version 20 for analysis.

In descriptive statistics; tables, graphs mean and frequency/percentage were used to present the information. Bivariate and multivariable logistic regression analysis was conducted to identify factors associated with suicidal ideation and attempt (independently) among persons living with HIV/AIDS. Only factors with $P$-value of $\leq 0.2$ on bivariate analyses was kept for multivariable logistic regression analyses and $95 \% \mathrm{CI}$ at $P$-value $<0.05$ was considered as statistically significant.

The standard method of entry (enter method) was used to select variables. Collinearity diagnostics for continuous variables and Spearman rank correlation for categorical variables was performed and there was no multicollinearity or significant correlation between predictor variables. Model fitness was checked using Hosmer and Lemeshow Test, P-value of 0.31 and 0.57 for suicidal ideation and attempt, respectively.

\section{Ethical considerations}

Ethical clearance was obtained from Debre Berhan University Institutional Review Board (IRB). Moreover, the investigator and data collectors have strived to protect and respect the privacy, secrecy, and wellbeing of participants with these conditions. The data collected for the purpose of this study never contained identifying information, thus ensuring the secrecy of the participants. All the data collected was used for the purpose of this study only. Participants was fully informed about the aims and methods of the study prior to starting the interview and informed written consent was obtained.

\section{Result}

A total of 348 individuals living with HIV/AIDS were planned to participate in this study and out of which 326 (93.7\%) participants completed the interview. A total of 22 non-respondent participants were due to; refusals to participate (13), and incomplete data (09).

\section{Socio-demographic characteristics}

The mean age of respondents was 39.2 (Standard deviation, $\mathrm{SD}=10.0)$. From the total study subjects, 326 $(42.9 \%)$ were married and $59.8 \%$ were female in gender. Majority, (92\%) of the participants were Orthodox Christian in religion. Almost $86 \%$ of the participants were living in an urban area; and $232(71.2 \%)$ were living with their family. Few of the respondents $(0.9 \%)$ who are living with HIV/AIDS were from prison. One hundred eight (33.1\%) participants attended primary education. Almost $29 \%$ of individuals (first quartile) earn less than 300 Ethiopian Birr (ETB). In this study, 63 (19.3\%) participants experienced hunger at least once because of lack of food in the previous month (Table 1).

\section{Clinical and HIV-related factors}

The clinical characteristics of the study participants is shown in (Table 2). Of the total individuals living with HIV/AIDS, $77.9 \%$ have at least one child; and $12.6 \%$ of these children are living with HIV/AIDS. Partners of participants (disclosure status of partner) who were living with HIV constitute $39 \%$ and the same proportion (39.3\%) have unknown HIV status. Almost $90 \%$ of responders were in clinical stage 1 of HIV/AIDS. Nearly all individuals started HAART; 312 (95.7\%) and 34 (10.4\%) who had started HAART were discontinued their ARV medication in a duration of treatment at least once. Off all the respondents; 60 (18.4\%) reported that they have known medical illness; and the majority, 27 (8.3\%) was comorbid mycobacterium infection. Few of the subjects, (10.7\%) had CD4 count less than 200 cells/ $\mu$ l.

From a total of 326 study participants; 24 (7.4\%) reported that they have previously diagnosed psychiatric illness. Mild comorbid depression and anxiety was reported as $12.3 \%$ and moderate-to-severe depression and anxiety to be $12.9 \%$. And, the study suggests $13.8 \%$ and $12.6 \%$ of the respondents have independent depression and anxiety, respectively. From the total participants of the study, $22(6.7 \%)$ had thought to kill themselves before they had known their HIV/AIDS status of positivity; and of them 18 (5.5\%) attempted suicide after the suicidal idea.

Participants self-rated their current health status and $251(77 \%)$ reported as having HIV with no symptoms. Two hundred twenty-eight (70\%) study subjects were found to be in a duration of 5 years and above since 
Table 1 Distribution of PLWHA by socio-demographic factors at selected public hospitals, North Shewa Zone, Amhara Region, Ethiopia, $2017(n=326)$

\begin{tabular}{|c|c|c|}
\hline Variables & Frequency & Percentage (\%) \\
\hline \multicolumn{3}{|l|}{ Age (in years) } \\
\hline $18-27$ & 28 & 8.6 \\
\hline $28-37$ & 121 & 37.1 \\
\hline $38-47$ & 104 & 31.9 \\
\hline$>=48$ & 73 & 22.4 \\
\hline Mean age $( \pm S D)$ & $39.20 \pm 10.0$ & \\
\hline \multicolumn{3}{|l|}{ Sex } \\
\hline Male & 131 & 40.2 \\
\hline Female & 195 & 59.8 \\
\hline \multicolumn{3}{|l|}{ Religion* } \\
\hline Orthodox & 300 & 92.0 \\
\hline Others & 26 & 8.0 \\
\hline \multicolumn{3}{|l|}{ Marital status } \\
\hline Married & 140 & 42.9 \\
\hline Never married & 59 & 18.1 \\
\hline Divorced & 81 & 24.8 \\
\hline Widowed & 46 & 14.1 \\
\hline \multicolumn{3}{|l|}{ Ethnicity* } \\
\hline Amhara & 300 & 92.0 \\
\hline Oromo & 22 & 6.7 \\
\hline Others & 4 & 1.2 \\
\hline \multicolumn{3}{|l|}{ Educational status } \\
\hline Informal education & 108 & 33.1 \\
\hline Primary education & 108 & 33.1 \\
\hline Secondary education & 64 & 19.6 \\
\hline Tertiary education & 46 & 14.1 \\
\hline \multicolumn{3}{|l|}{ Employment status } \\
\hline Unemployed/none & 27 & 8.3 \\
\hline Productive & 58 & 17.8 \\
\hline Income generating & 241 & 73.9 \\
\hline \multicolumn{3}{|l|}{ Place of residence } \\
\hline Urban & 280 & 85.9 \\
\hline Rural & 46 & 14.1 \\
\hline \multicolumn{3}{|l|}{ Average monthly income } \\
\hline$<300$ ETB & 94 & 28.8 \\
\hline 300-879 ETB & 69 & 21.2 \\
\hline 880-1800 ETB & 85 & 26.1 \\
\hline$>1800$ ETB & 78 & 23.9 \\
\hline \multicolumn{3}{|l|}{ Hunger in the last month } \\
\hline Yes & 63 & 19.3 \\
\hline No & 263 & 80.7 \\
\hline \multicolumn{3}{|l|}{ Current living status } \\
\hline Living with family & 245 & 75.2 \\
\hline Living alone & 81 & 24.8 \\
\hline
\end{tabular}

* Others (religion = Muslim, Protestant, Catholic; Ethnicity=Afar, Gurage, Tigre) diagnosis for HIV. Almost 34.5\% of respondents have family member with HIV infection. A total of 293 (89.9\%) participants disclosed their HIV status to significant others; and of them 213 (65.3\%) choose their parent (father or mother) who should be told about their personal decision of disclosing. Only 133 (40.8\%) of married individuals have got balance of honesty from their spouse to hear their HIV status disclosure.

\section{Psychosocial factors}

From the total individuals included in the study (326), $265(81.3 \%)$ considered oneself as spiritual and 69.9\% rate the importance of being spiritual as important. Less than half of participants (45.4\%) have perceived and labeled under having moderate-to-strong social support (Table 3).

In the dimension of physical and sexual abuse, 15 (4.6\%) have been hit, slapped, kicked, or otherwise physically hurt by someone since they are found to have seropositive status disclosure; 7 (2.1\%) also had history of forced sexual intercourse in life time. In the stigma domain, 192 (58.9\%) subjects were never aware of being gossiped because of their HIV status (Table 3).

\section{Substance use characteristics of the respondents}

From the total individuals involved in the study, $6.1 \%$, $45.7 \%$ and $11.3 \%$ use tobacco, alcohol and khat at least once in their life time, respectively. Among ever users, current use (last 3 months use) was three (15.0\%), 97 (65.1\%) and 9 (24.3\%) for tobacco, alcohol and khat, respectively (Table 4).

\section{Prevalence of suicidal ideation and attempt}

Among the total of 326 study subjects, those who replied "Yes" for suicidal ideation and attempt questions was considered having suicidal idea and attempt. Therefore, the overall prevalence of suicidal ideation and attempt among HIV/AIDS patients after knowing their seropositive status was $16 \%(95 \%$ CI $12.3,19.9)$ and $7.1 \%$ (95\% CI 4.6, 9.8), respectively (Fig. 1).

From the overall prevalence of suicidal attempt (7.1\%), $34.8 \%$ of participants attempted suicide in the last month of the study period, and the majority (73.9\%) used poisoning as a method of suicidal attempt. The primarily held reason for suicidal attempt was fear of the consequence of HIV, i.e., physical illness and stigma (60.9\%). Among 23 individuals who attempted suicide since HIV status known, eight (34.8\%) attempted suicide within 1 month of knowing HIV seropositive status (Table 5).

Factors associated with suicidal ideation and attempt Low monthly income, living alone, suicidal thought before knowing seropositive status, family history of 


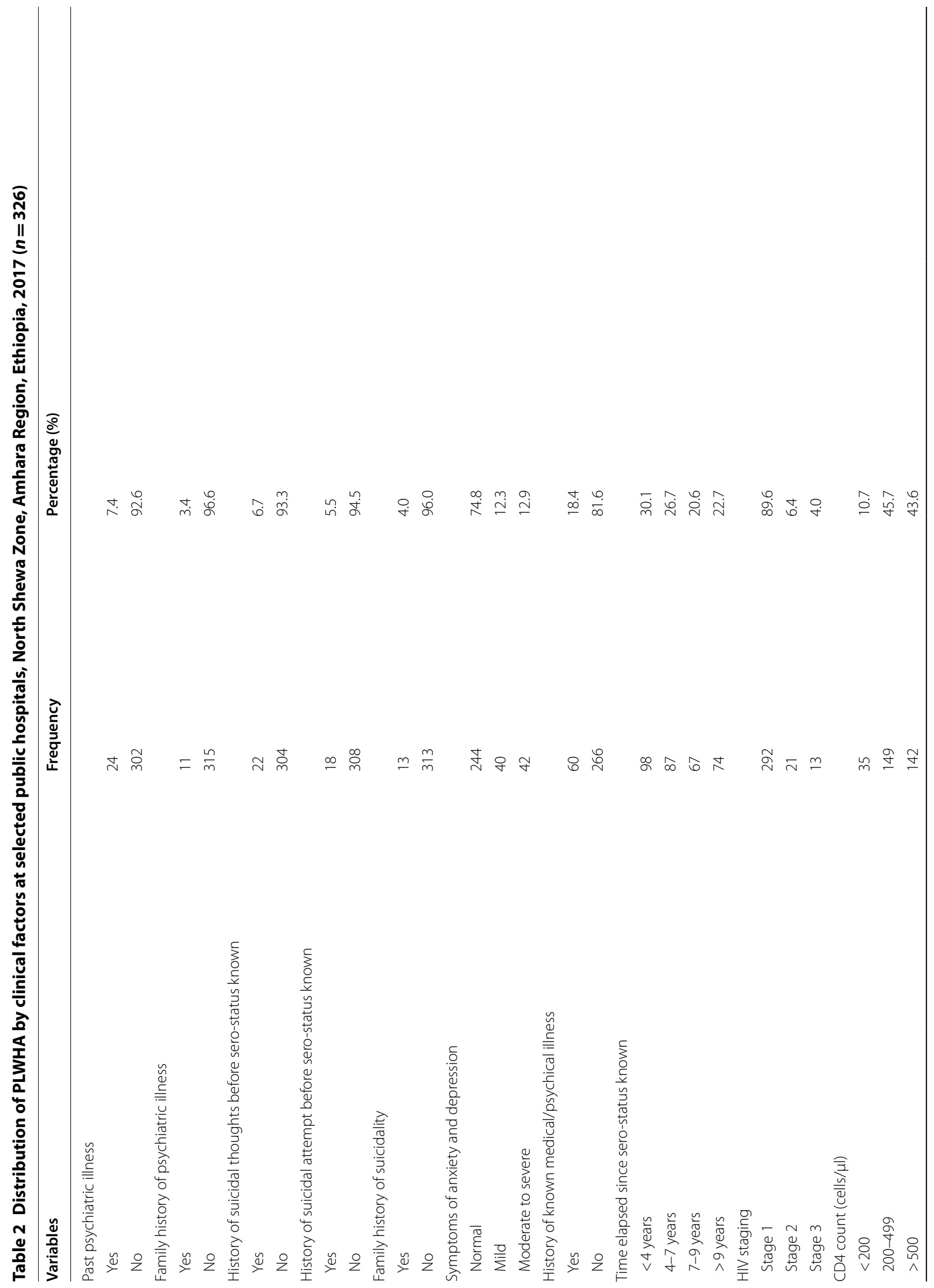




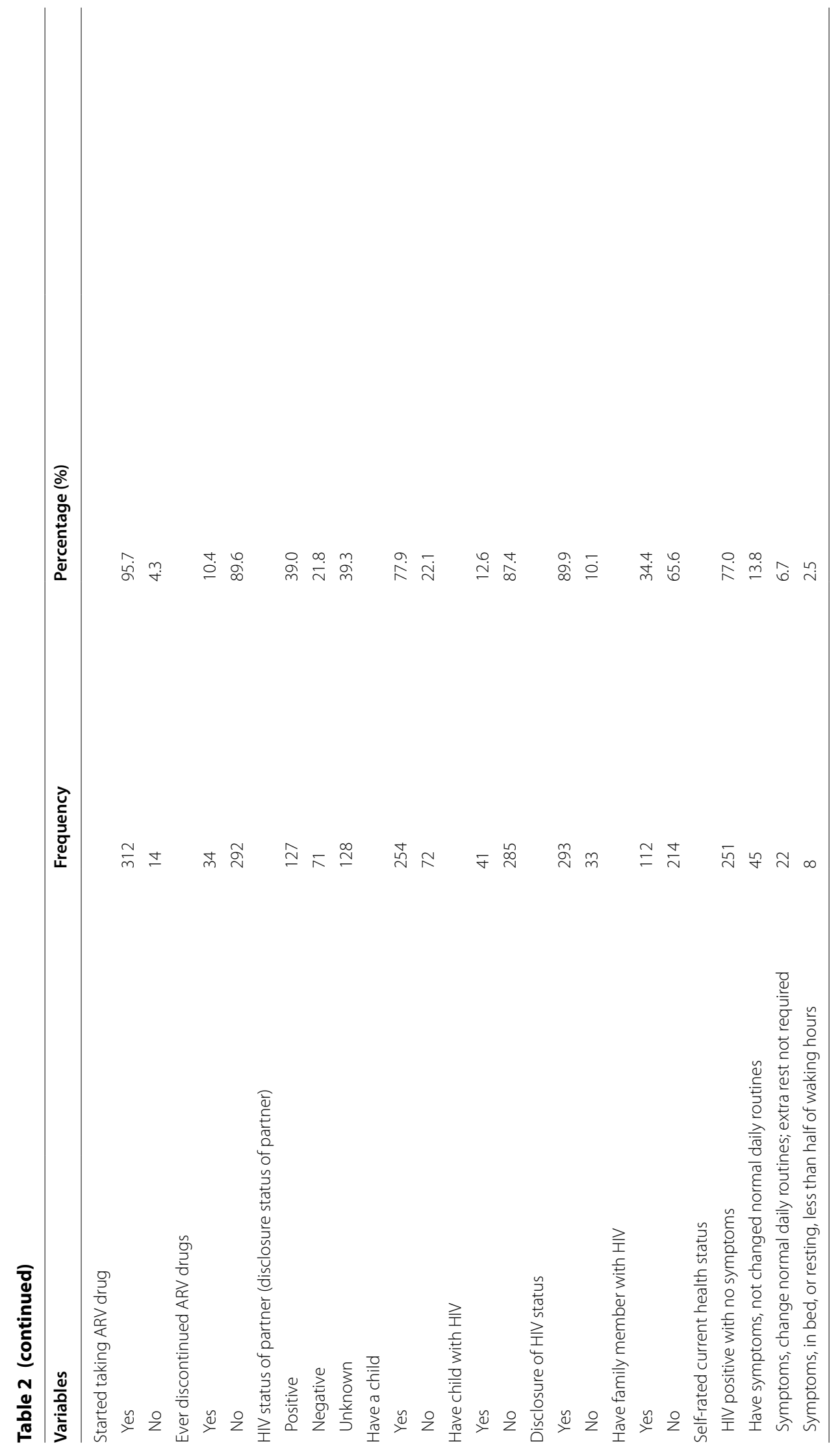


Table 3 Distribution of PLWHA by psychosocial factors and social support at selected public hospitals, North Shewa Zone, Amhara Region, Ethiopia, 2017 ( $n=326$ )

\begin{tabular}{|c|c|c|}
\hline Variables & Frequency & Percentage (\%) \\
\hline \multicolumn{3}{|c|}{ Physical abuse since sero-status known (hit, slapped, kicked, or physically hurt someone?) } \\
\hline Yes & 15 & 4.6 \\
\hline No & 311 & 95.4 \\
\hline \multicolumn{3}{|l|}{ Ever history of forced sex } \\
\hline Yes & 7 & 2.1 \\
\hline No & 319 & 97.9 \\
\hline \multicolumn{3}{|l|}{ Social support } \\
\hline Poor support & 178 & 54.6 \\
\hline Moderate-to-strong support & 148 & 45.4 \\
\hline \multicolumn{3}{|c|}{ History of gossip with the last 12 months because of HIV status } \\
\hline Often & 35 & 10.7 \\
\hline Sometimes & 67 & 20.6 \\
\hline Hardly ever & 32 & 9.8 \\
\hline Never & 192 & 58.9 \\
\hline \multicolumn{3}{|c|}{ Excluded from social gatherings or activities in the last 12 months } \\
\hline Often & 41 & 12.6 \\
\hline Sometimes & 64 & 19.6 \\
\hline Hardly ever & 33 & 10.1 \\
\hline Never & 188 & 57.7 \\
\hline \multicolumn{3}{|c|}{ Consider oneself spiritual or religious } \\
\hline Yes & 265 & 81.3 \\
\hline No & 61 & 18.7 \\
\hline \multicolumn{3}{|c|}{ Rate of importance of faith/belief in life (mean score of scale from 0 to 5) } \\
\hline Important $(>=3.96)$ & 228 & 69.9 \\
\hline Not important $(<3.96)$ & 98 & 30.1 \\
\hline
\end{tabular}

suicide, experiencing mild and moderate-to-severe depression and anxiety symptoms, being gossiped sometimes in the last 12 months of the study period due to HIV status and ever use of khat (a psychoactive substance) was statistically associated factors with suicidal ideation (Table 6). And low monthly income, experiencing mild and moderate-to-severe depression and anxiety symptoms, being gossiped sometimes and often in the previous 12 months of the study period due to HIV status and using alcohol currently were factors independently associated with suicidal attempt (Table 7).

\section{Discussion}

\section{Prevalence of suicidal ideation and associated factors}

The overall magnitude of suicidal ideation in this study was $16 \%(95 \%$ CI $12.3,19.9)$. This result shows that significant proportion of people living with retroviral infection had a mental health problem of suicidal ideation. Hence, assessing suicidal ideation and giving appropriate intervention should become a substantial concern for professionals working at HIV/AIDS clinics.
The magnitude of suicidal ideation in this study was in line with the study done in HIV clinics of university of Washington and Alabama; 14\% [9], US cities; 19\% [46] and South Africa; $17.1 \%$ within 3 days after knowing HIV status [47]. The reason for the consistency of magnitude might be due to similar nature of the retroviral disease infection across regions such as: chronicity, decreased functioning (declining all dimensions of health), and the virus effect on the central nervous system (imposing cognitive decline) can lead to possible rational thinking loss, depression and other related mental disorders which in turn result in an increased vulnerability of PLWHA prone to thought about suicide.

The magnitude of suicidal ideation in this study was lower than those studies conducted in North America; 26\% [14], Virginia Commonwealth University; 26\% [48], Texas; 59\% [49], South East London; 31\% [22], Chelsea and London; 26.9\% [32], Nigeria; Benin, and 34.7\% [50]. The lower magnitude of suicidal ideation in this study might be due to the level of practical social support. As the fact that in developing countries including Ethiopia, there is strong social support and religion also has major 
Table 4 Distribution of PLWHA by substance use characteristics at selected public hospitals, North Shewa Zone, Amhara Region, Ethiopia, 2017 ( $n=326)$

\begin{tabular}{lcc}
\hline Variables & Frequency & Percentage (\%) \\
\hline Ever use of tobacco & 20 & 6.1 \\
Yes & 306 & 93.9 \\
No & & \\
Ever use alcohol & 149 & 45.7 \\
Yes & 177 & 54.3 \\
No & & \\
Ever use khat & 37 & 11.3 \\
Yes & 289 & 88.7 \\
No & & \\
Current use of tobacco & 3 & 0.9 \\
Yes & 323 & 99.1 \\
No & & \\
Current use alcohol & 97 & 29.8 \\
Yes & 229 & 70.2 \\
No & & 2.8 \\
Current use khat & 9 & 97.2 \\
Yes & 317 & \\
No & & \\
\hline
\end{tabular}

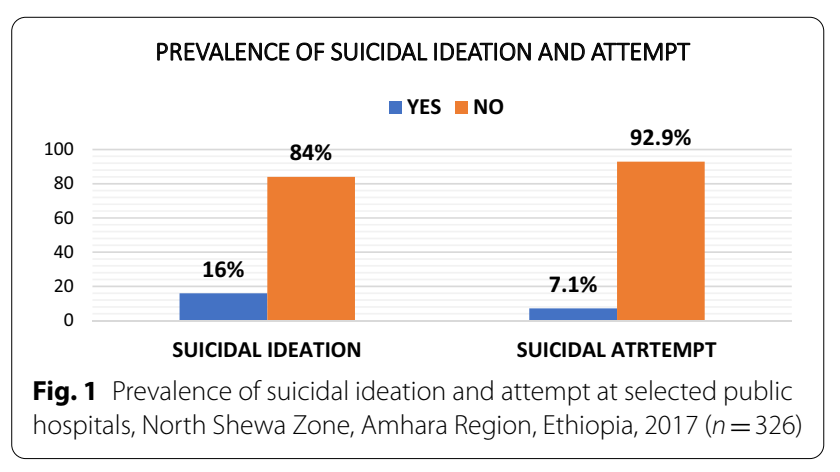

role not to think about suicide. Increased level of understanding about nature and chronicity of the disease by HIV infected individuals, and presence (access and availability) of treatment for HIV/AIDS these days could also contribute for PLWHA to have a lower suicidal thought.

The magnitude of suicidal ideation in this study was higher than studies done using general population sample in Addis Ababa; 2.7\% [26]. The difference might be due to difference in outcome of interest, literacy status, sample size, and study population. The study done at Addis Ababa aimed to current suicidal ideation and used urban representative sample $(N=10,203)$. Additionally, living in capital city may possibility increase the literacy rate of the study subjects; and probably may get information about how to live longer with retroviral disease by adhering to ARV drugs.

Thinking about suicide among PLWHA in this study was lower than a report on people having mental illness (64.8\%), from a psychiatric clinic in Gondar Hospital [24]. Compared to previous studies in Ethiopia, our study reports a lower suicidal ideation prevalence: $22.5 \%$ at Zewditu Memorial Hospital, Addis Ababa [28]; 33.6\% at Debark Hospital, North Gondar [29]; and 24.3\% at Hiwot Fana Specialized Hospital, Harar [30]. This variation might be explained by the difference of study settings that our study mainly includes primary health care services which predominantly serves rural residents and under reporting is expected as a result of social desirability issue in fear of stigma, and lower literacy rate might cause limited awareness about psychological, social and physical impact of HIV/AIDS likely leading to reserved true responses of deicidal thoughts.

This study found that suicidal ideation was significantly associated among study subjects who have been gaining less than 300 Ethiopian Birr per month as compared with study subjects who earn greater than 1800 Ethiopian Birr. This result is consistent with the study conducted in New York City [51], US cities [46]. This finding might be due to that individuals who earn low monthly income which causes possible financial distress are unable to fulfill basic needs; have potential nutritional deficit and may impose external effect on participants emotional and psychological wellbeing.

Living alone was significantly associated with suicidal ideation as compared with individuals living with significant others and consistent with the study done in New York city [51], US cities [46], Puerto Rico [27] and South Africa [47]. The possible explanation for this consistency seems that being living with others is supportive and basic for emotional and social support; as supportive environment decreases the sense of isolation and not to think about suicide.

Having suicidal thoughts before knowing HIV status was statistically significant factor for current suicidal ideation. The association was in the same way of the studies done in semi-urban Uganda [11]. The association might be due to having previous suicidal thoughts increases the vulnerability of individuals to thought about suicidal after knowing the HIV status. Having family history of suicide was also significantly associated with suicidal ideation. This association might be possibly due to individuals who had suicide among their first-degree relatives are genetically prone for suicidality.

Study subjects who experienced mild and moderate-tosevere depression and anxiety symptoms had higher odds to have suicidal ideation as compared with individuals who had no symptoms. This finding is consistent with the 
Table 5 Summary table for suicidal ideation and attempt characteristics at selected public hospitals, North Shewa Zone, Amhara Region, Ethiopia, 2017

\begin{tabular}{|c|c|c|}
\hline Variables & Frequency & Percentage (\%) \\
\hline \multicolumn{3}{|l|}{ Suicidal ideation $(n=326)$} \\
\hline Yes & 52 & 16.0 \\
\hline No & 274 & 84.0 \\
\hline \multicolumn{3}{|l|}{ Duration of suicidal thought since HIV status known $(n=52)$} \\
\hline Within a month (<=1 month) & 34 & 65.4 \\
\hline $1-3$ months & 12 & 23.1 \\
\hline More than 3 months ( $>=3$ months) & 6 & 11.5 \\
\hline \multicolumn{3}{|l|}{ Suicidal idea with in the last one month $(n=52)$} \\
\hline Yes & 15 & 28.8 \\
\hline No & 37 & 71.2 \\
\hline \multicolumn{3}{|l|}{ Suicidal plan after HIV status known $(n=52)$} \\
\hline Yes & 31 & 59.6 \\
\hline No & 21 & 40.4 \\
\hline \multicolumn{3}{|l|}{ Suicidal attempt $(n=326)$} \\
\hline Yes & 23 & 7.1 \\
\hline No & 303 & 92.9 \\
\hline \multicolumn{3}{|l|}{ Planned suicidal attempt $(n=23)$} \\
\hline Yes & 21 & 91.3 \\
\hline No & 2 & 8.7 \\
\hline \multicolumn{3}{|l|}{ Attempted suicide among planned suicide $(n=31)$} \\
\hline Yes & 21 & 67.7 \\
\hline No & 10 & 32.3 \\
\hline \multicolumn{3}{|l|}{ Duration of suicidal attempt since HIV status known $(n=23)$} \\
\hline Within a month ( $<=1$ month) & 18 & 78.3 \\
\hline $1-3$ months & 2 & 8.7 \\
\hline More than 3 months ( $>=3$ months) & 3 & 13.0 \\
\hline \multicolumn{3}{|l|}{ Suicidal attempt with in the last one month $(n=23)$} \\
\hline Yes & 8 & 34.8 \\
\hline No & 15 & 65.2 \\
\hline \multicolumn{3}{|l|}{ Frequency of suicidal attempt $(n=23)$} \\
\hline One attempt & 13 & 56.5 \\
\hline Two attempts & 4 & 17.4 \\
\hline Three or more attempts & 6 & 26.1 \\
\hline \multicolumn{3}{|l|}{ Methods used for attempted suicide $(n=23)$} \\
\hline Hanging & 3 & 13.0 \\
\hline Poisoning & 17 & 73.9 \\
\hline Others (jumping, electric shock) & 3 & 13.0 \\
\hline \multicolumn{3}{|l|}{ Self-reported reason for attempted suicide $(n=23)$} \\
\hline Poverty & 5 & 21.7 \\
\hline Fear of HIV (physical illness, stigma) & 14 & 60.9 \\
\hline Other reasons/combinations & 4 & 17.4 \\
\hline \multicolumn{3}{|l|}{ Response most describes the seriousness of the suicidal attempt $(n=23)$} \\
\hline Serious attempt to kill oneself and it was only luck that didn't succeed & 7 & 30.4 \\
\hline Tried to kill oneself, but the method was not fool-proof & 13 & 56.5 \\
\hline Attempt was cry for help, and did not intend to die & 3 & 13.0 \\
\hline
\end{tabular}


Table 6 Bivariate and multivariable logistic regression analysis for factors associated with suicidal ideation among PLWHA at selected public hospitals, North Shewa Zone, Ethiopia, $2017(n=326)$

\begin{tabular}{|c|c|c|c|c|}
\hline \multirow[t]{2}{*}{ Variables } & \multicolumn{2}{|c|}{ Suicidal ideation } & \multirow[t]{2}{*}{ COR $(95 \% \mathrm{Cl})$} & \multirow[t]{2}{*}{ AOR $(95 \% \mathrm{Cl})$} \\
\hline & Yes & No & & \\
\hline \multicolumn{5}{|l|}{ Age (in years) } \\
\hline $18-27$ & 4 & 24 & 1.00 & 1.00 \\
\hline $28-37$ & 24 & 97 & $1.49(0.47,4.68)$ & $2.30(0.36,14.50)$ \\
\hline $38-47$ & 18 & 86 & $1.26(0.39,4.06)$ & $2.13(0.32,14.03)$ \\
\hline$>=48$ & 6 & 67 & $0.54(0.14,2.07)$ & $0.55(0.06,4.74)$ \\
\hline \multicolumn{5}{|l|}{ Marital status } \\
\hline Married & 16 & 124 & 1.00 & 1.00 \\
\hline Never married & 11 & 48 & $1.78(0.77,4.10)$ & $1.68(0.46,6.14)$ \\
\hline Divorced & 18 & 63 & $2.21(1.06,4.63)$ & $2.03(0.64,6.46)$ \\
\hline Widowed & 7 & 39 & $1.39(0.53,3.63)$ & $0.61(0.13,2.87)$ \\
\hline \multicolumn{5}{|l|}{ Ethnicity } \\
\hline Amhara & 45 & 255 & $0.18(0.02,1.29)$ & $0.13(0.002,10.77)$ \\
\hline Oromo & 5 & 17 & $0.29(0.03,2.65)$ & $0.09(0.001,9.84)$ \\
\hline Others & 2 & 2 & 1.00 & 1.00 \\
\hline \multicolumn{5}{|l|}{ Employment status } \\
\hline Unemployed/none & 8 & 19 & $2.25(0.92,5.51)$ & $1.01(0.20,5.09)$ \\
\hline Productive & 6 & 52 & $0.62(0.25,1.54)$ & $0.43(0.12,1.52)$ \\
\hline Income generating & 38 & 203 & 1.00 & 1.00 \\
\hline \multicolumn{5}{|l|}{ average monthly income } \\
\hline$<300$ ETB & 23 & 71 & $4.73(1.70,13.13)$ & $4.02(1.20,3.51) *$ \\
\hline 300-879 ETB & 11 & 58 & $2.77(0.91,8.42)$ & $1.87(0.52,6.72)$ \\
\hline 880-1800 ETB & 13 & 72 & $2.64(0.89,7.78)$ & $1.44(0.41,5.04)$ \\
\hline$>1800$ ETB & 5 & 73 & 1.00 & 1.00 \\
\hline \multicolumn{5}{|l|}{ Hunger in the last month } \\
\hline Yes & 17 & 46 & $2.41(1.24,4.66)$ & $0.64(0.20,2.07)$ \\
\hline No & 35 & 228 & 1.00 & 1.00 \\
\hline \multicolumn{5}{|l|}{ Current living status } \\
\hline Living with family & 32 & 213 & 1.00 & 1.00 \\
\hline Living alone & 20 & 61 & $2.18(1.17,4.09)$ & $2.46(1.05,5.74) *$ \\
\hline \multicolumn{5}{|l|}{ Past psychiatric illness } \\
\hline Yes & 7 & 17 & $2.35(0.92,5.99)$ & $0.58(0.11,3.05)$ \\
\hline No & 45 & 257 & 1.00 & 1.00 \\
\hline \multicolumn{5}{|l|}{ History of suicidal thoughts before HIV status known } \\
\hline Yes & 15 & 7 & $15.46(5.92,40.42)$ & $4.33(0.84,22.36)$ \\
\hline No & 37 & 267 & 1.00 & 1.00 \\
\hline \multicolumn{5}{|l|}{ History of suicidal attempt before HIV status known } \\
\hline Yes & 15 & 3 & $36.62(10.12,132.55$ & $8.74(1.30,58.88) *$ \\
\hline No & 37 & 271 & 1.00 & 1.00 \\
\hline \multicolumn{5}{|l|}{ Family history of suicidality } \\
\hline Yes & 8 & 5 & $9.78(3.06,31.26)$ & $5.79(1.34,25.08) *$ \\
\hline No & 44 & 269 & 1.00 & 1.00 \\
\hline \multicolumn{5}{|l|}{ Started taking ARV drug } \\
\hline Yes & 48 & 264 & 1.00 & 1.00 \\
\hline No & 4 & 10 & $2.20(0.66,7.30)$ & $1.42(0.25,8.09)$ \\
\hline \multicolumn{5}{|l|}{ Self-rated current health status } \\
\hline HIV positive with no symptoms & 31 & 220 & 1.00 & 1.00 \\
\hline Have symptoms, not changed normal daily routines & 16 & 29 & $3.92(1.91,8.02)$ & $2.10(0.81,5.48)$ \\
\hline
\end{tabular}


Table 6 (continued)

\begin{tabular}{|c|c|c|c|c|}
\hline \multirow[t]{2}{*}{ Variables } & \multicolumn{2}{|c|}{ Suicidal ideation } & \multirow[t]{2}{*}{$\operatorname{COR}(95 \% \mathrm{CI})$} & \multirow[t]{2}{*}{ AOR $(95 \% \mathrm{Cl})$} \\
\hline & Yes & No & & \\
\hline Symptoms, change normal daily routines; extra rest not required & 4 & 18 & $1.58(0.50,4.97)$ & $0.24(0.04,1.36)$ \\
\hline Symptoms, in bed, or resting, less than half of waking hours & 1 & 7 & $1.01(0.12,8.52)$ & $0.08(0.002,3.03)$ \\
\hline \multicolumn{5}{|l|}{ Symptoms of anxiety and depression } \\
\hline Normal & 23 & 221 & 1.00 & 1.00 \\
\hline Mild & 13 & 27 & $4.63(2.10,10.18)$ & $5.78(2.13,15.75)^{* * *}$ \\
\hline Moderate to severe & 16 & 26 & $5.91(2.78,12.60)$ & $5.47(2.01,14.88)^{* * *}$ \\
\hline \multicolumn{5}{|l|}{ Social support } \\
\hline Poor support & 34 & 144 & $1.71(0.92,3.17)$ & $1.08(0.42,2.75)$ \\
\hline Moderate-to-strong support & 52 & 274 & 1.00 & 1.00 \\
\hline \multicolumn{5}{|l|}{ History of gossip with the last 12 months because of HIV status } \\
\hline Often & 11 & 24 & $4.43(1.87,10.50)$ & $2.38(0.60,9.50)$ \\
\hline Sometimes & 16 & 51 & $3.03(1.44,6.37)$ & $3.26(1.07,9.97) *$ \\
\hline Hardly ever & 7 & 25 & $2.71(1.03,7.13)$ & $1.36(0.31,6.02)$ \\
\hline Never & 18 & 174 & 1.00 & 1.00 \\
\hline \multicolumn{5}{|l|}{ Consider oneself spiritual or religious } \\
\hline Yes & 37 & 228 & 1.00 & 1.00 \\
\hline No & 15 & 46 & $2.01(1.02,3.96)$ & $1.17(0.36,3.84)$ \\
\hline \multicolumn{5}{|l|}{ Rate of importance of faith/belief in life (mean score of scale from 0 to 5) } \\
\hline Important $(>=3.96)$ & 32 & 196 & 1.00 & 1.00 \\
\hline Not important $(<3.96)$ & 20 & 78 & $1.57(0.85,2.91)$ & $1.25(0.43,3.70)$ \\
\hline \multicolumn{5}{|l|}{ Ever use of tobacco } \\
\hline Yes & 6 & 14 & $2.42(0.89,6.63)$ & $0.89(0.17,4.66)$ \\
\hline No & 46 & 260 & 1.00 & 1.00 \\
\hline \multicolumn{5}{|l|}{ Ever use of khat } \\
\hline Yes & 13 & 24 & $3.47(1.63,7.38)$ & $5.58(2.08,14.98) * * *$ \\
\hline No & 52 & 274 & 1.00 & 1.00 \\
\hline \multicolumn{5}{|l|}{ Current use of khat } \\
\hline Yes & 3 & 6 & $2.74(0.66,11.30)$ & $0.51(0.05,4.75)$ \\
\hline No & 49 & 268 & 1.00 & 1.00 \\
\hline
\end{tabular}

*P value is significant at $P<0.05{ }^{* *} \mathrm{P}$ value is significant at $P<0.01,{ }^{* * *} \mathrm{P}$ value is significant at $P \leq 0.001,1.00=$ reference for category, $P$ value of Hosmer and Lemeshow test $=0.31$

finding of the studies done in New York City [51], Virginia Commonwealth University [48], Puerto Rico [52] and semi-urban Uganda [11]. The possible reason for the consistency might be the fact that individuals who suffer depression and anxiety symptoms are at higher risk of thinking about suicide due to hopelessness, worthlessness, and excessive and uncontrollable thoughts.

Ever use of khat (a psychoactive substance) is associated with suicidal ideation as compared with who did not use. This finding is in agreement with studies done in New York City [51], US cities [46] and Virginia Commonwealth University that substance or drug abuse (dependence) like intravenous drug use, cocaine use, and alcohol use were reported to be associated with suicidal ideation [48]. This consistency might be due to individuals who abuse psychoactive substances (like khat) are vulnerable to think about suicide due to declining health and the substance direct effect to the brain.

A psychosocial factor like being gossiped sometimes in the previous 12 months of study period due to the status of HIV positive were significantly associated for suicidal ideation as compared with individuals who did not witness gossip. This finding is in line with studies done in New York City [51]. The possible explanation for the association might be as a result of gossip for the status of HIV infection plays important role in thinking of suicide and feeling of stigmatized can make people more vulnerable for thinking suicidality. 
Table 7 Bivariate and multivariable logistic regression analysis for factors associated with suicidal attempt among PLWHA at selected public hospitals, North Shewa Zone, Ethiopia, $2017(n=326)$

\begin{tabular}{|c|c|c|c|c|}
\hline \multirow[t]{2}{*}{ Variables } & \multicolumn{2}{|c|}{ Suicidal attempt } & \multirow[t]{2}{*}{ COR $(95 \% \mathrm{Cl})$} & \multirow[t]{2}{*}{ AOR $(95 \% \mathrm{Cl})$} \\
\hline & Yes & No & & \\
\hline \multicolumn{5}{|l|}{ Marital status } \\
\hline Married & 6 & 134 & 1.00 & 1.00 \\
\hline Never married & 5 & 54 & $1.78(0.77,4.10)$ & $2.60(0.55,12.24)$ \\
\hline Divorced & 10 & 71 & $2.21(1.06,4.63)$ & $2.42(0.52,11.32)$ \\
\hline Widowed & 2 & 44 & $1.39(0.53,3.63)$ & $0.58(0.08,4.20)$ \\
\hline \multicolumn{5}{|l|}{ Employment status } \\
\hline Unemployed/none & 5 & 22 & $3.42(1.14,10.32)$ & $1.66(0.25,11.11)$ \\
\hline Productive & 3 & 55 & $0.82(0.23,2.94)$ & $0.46(0.10,2.15)$ \\
\hline Income generating & 15 & 226 & 1.00 & 1.00 \\
\hline \multicolumn{5}{|l|}{ Place of residence } \\
\hline Urban & 22 & 258 & 1.00 & 1.00 \\
\hline Rural & 1 & 45 & $0.26(0.03,1.98)$ & $0.19(0.02,1.72)$ \\
\hline \multicolumn{5}{|l|}{ Average monthly income } \\
\hline$<300$ ETB & 10 & 84 & $9.17(1.15,73.28)$ & $11.55(1.12,18.86)^{*}$ \\
\hline 300-879 ETB & 3 & 66 & $3.50(0.36,34.46)$ & $3.57(0.28,45.98)$ \\
\hline 880-1800 ETB & 9 & 76 & $9.12(0.13,73.73)$ & $9.21(0.92,91.84)$ \\
\hline$>1800$ ETB & 1 & 77 & 1.00 & 1.00 \\
\hline \multicolumn{5}{|l|}{ Hunger in the last month } \\
\hline Yes & 9 & 54 & $2.96(1.22,7.20)$ & $1.64(0.45,5.96)$ \\
\hline No & 14 & 249 & 1.00 & 1.00 \\
\hline \multicolumn{5}{|l|}{ Past psychiatric illness } \\
\hline Yes & 5 & 19 & $4.15(1.39,12.40)$ & $2.893(0.573,14.614)$ \\
\hline No & 18 & 284 & 1.00 & 1.00 \\
\hline \multicolumn{5}{|l|}{ Family history of suicidality } \\
\hline Yes & 3 & 10 & $4.40(1.12,7.25)$ & $5.099(0.80,32.499)$ \\
\hline No & 20 & 293 & 1.00 & 1.00 \\
\hline \multicolumn{5}{|l|}{ Self-rated current health status } \\
\hline HIV positive with no symptoms & 12 & 239 & 1.00 & 1.00 \\
\hline Have symptoms, not changed normal daily routines & 8 & 37 & $4.31(1.65,11.24)$ & $1.37(0.35,5.33)$ \\
\hline Symptoms, change normal daily routines; extra rest not required & 2 & 20 & $1.99(0.42,9.53)$ & $0.43(0.05,3.98)$ \\
\hline Symptoms, in bed, or resting, less than half of waking hours & 1 & 7 & $2.85(0.32,25.02)$ & $0.17(0.01,5.74)$ \\
\hline \multicolumn{5}{|l|}{ Symptoms of anxiety and depression } \\
\hline Normal & 8 & 236 & 1.00 & 1.00 \\
\hline Mild & 7 & 33 & $6.26(2.13,18.39)$ & $5.44(1.64,18.07) * *$ \\
\hline Moderate to severe & 8 & 34 & $6.94(2.44,19.71)$ & $4.46(1.40,14.25)^{*}$ \\
\hline \multicolumn{5}{|l|}{ History of gossip with the last 12 months because of HIV status } \\
\hline Often & 7 & 28 & $6.61(2.16,20.26)$ & $4.98(1.38,17.93)^{*}$ \\
\hline Sometimes & 8 & 59 & $3.58(1.25,10.30)$ & $5.14(1.51,17.52)^{* *}$ \\
\hline Hardly ever & 1 & 31 & $0.85(0.10,7.17)$ & $0.77(0.07,8.01)$ \\
\hline Never & 7 & 185 & 1.00 & 1.00 \\
\hline \multicolumn{5}{|l|}{ Consider oneself spiritual or religious } \\
\hline Yes & 15 & 250 & 1.00 & 1.00 \\
\hline No & 8 & 53 & $2.52(1.02,6.24)$ & $2.76(0.94,8.13)$ \\
\hline \multicolumn{5}{|l|}{ Rate of importance of faith/belief in life (mean score of scale from 0 to 5) } \\
\hline Important $(>=3.96)$ & 13 & 215 & 1.00 & 1.00 \\
\hline Not important $(<3.96)$ & 10 & 88 & $1.88(0.80,4.45)$ & $0.98(0.27,3.60)$ \\
\hline Ever use of tobacco & & & & \\
\hline
\end{tabular}


Table 7 (continued)

\begin{tabular}{|c|c|c|c|c|}
\hline \multirow[t]{2}{*}{ Variables } & \multicolumn{2}{|c|}{ Suicidal attempt } & \multirow[t]{2}{*}{ COR $(95 \% \mathrm{Cl})$} & \multirow[t]{2}{*}{ AOR $(95 \% \mathrm{Cl})$} \\
\hline & Yes & No & & \\
\hline Yes & 3 & 17 & $2.52(0.68,9.34)$ & $1.51(0.12,19.65)$ \\
\hline No & 20 & 286 & 1.00 & 1.00 \\
\hline \multicolumn{5}{|c|}{ Current use of tobacco } \\
\hline Yes & 1 & 2 & $6.84(0.60,78.42)$ & $3.78(0.05,285.73)$ \\
\hline No & 22 & 301 & 1.00 & 1.00 \\
\hline \multicolumn{5}{|c|}{ Current use of alcohol } \\
\hline Yes & 11 & 86 & $2.31(0.98,5.44)$ & $3.34(1.21,9.25)^{*}$ \\
\hline No & 12 & 217 & 1.00 & 1.00 \\
\hline \multicolumn{5}{|c|}{ Ever use of khat } \\
\hline Yes & 5 & 32 & $2.35(0.82,6.77)$ & $2.05(0.34,12.52)$ \\
\hline No & 18 & 271 & 1.00 & 1.00 \\
\hline
\end{tabular}

*P value is significant at $P<0.05,{ }^{* *} P$ value is significant at $P<0.01,{ }^{* * *} P$ value is significant at $P \leq 0.001,1.00=$ reference for category, $P$ value of Hosmer and Lemeshow test $=0.57$

\section{Prevalence of suicidal attempt and associated factors}

The overall magnitude of suicidal attempt in this study was $7.1 \%$ (95\% CI 4.6, 9.8). This result shows that significant proportion of people living with retroviral disease had attempted to kill themselves. Hence, assessing history of attempting suicide and giving immediate intervention should become a substantial concern for professionals working at HIV/AIDS clinics.

The magnitude of suicidal attempt in this study was in line with the study done in semi urban Uganda; 7.8\% [11] and Nigeria (Benin); 9.3\% [50]. This agreement in magnitude might be due to health literacy, weak interdepartmental communication, and tendency of high HIV infection-related stigmatization in African countries. Health literacy has important role for attempting suicide; as individuals had an information about the possibility of living longer with HIV, and attempting suicide would be less likely. The service fragmentation between HIV clinics and psychiatric clinics in African countries might have been played major role for the lack of screening suicide and giving psychological interventions. Stigma associated with HIV infection is higher in African countries [53] and the immediate outcome of stigma might be attempting suicide due to the feeling of isolation, loneliness and clouding of future life.

The magnitude of attempting suicide after knowing HIV status of positivity in the current study is lower than the studies done in North American medical centers; 13\% [14], New York City; 26\% [54], Texas; 50\% [49], Puerto Rico; 22\% [52], Chelsea and London; 20\% [32]. This variation might be due to under reporting of suicidal attempt in fear of the social desirability issue of participants (disclosing suicidality might be considered as a personal weakness) in our study and the effect of religion, that suicide is considered as an additional sin in the view of some religious doctrines in our setting.

Studies using general population sample at Addis Ababa among 10,203 adults [26], and Butajira, Ethiopia [25] reported a lower prevalence of life time suicidal attempt; $0.9 \%$ and $3.2 \%$, respectively, compared to our study finding. The difference in magnitude estimation might be due to the time of the study (far earlier in previous studies), sample size, study area and population of interest that general population comprises a mix of healthy, and mentally or medically ill individuals including HIC/AIDS. Like previous discussion on suicidal ideation section above, reported suicidal attempt in this study was lower compared to people with mental illnesses in rural Ethiopia [23] and psychiatric clinic at University of Gondar [24]. Similarly, compared to previous studies in Ethiopia, our study shows a lower suicidal attempt prevalence: $13.9 \%$ at Zewditu Memorial Hospital, Addis Ababa [28]; 20.1\%, at Debark Hospital, North Gondar [29]; and $12.6 \%$ at Hiwot Fana Specialized Hospital, Harar [30].

This study found that suicidal attempt was higher among study subjects who have less than 300 ETB monthly income as compared with study subjects who gain greater than 1800 ETB. This result is consistent with the study conducted in New York City [51], US cities [46]. This finding might be because individuals who earn low monthly income (possible cause of financial distress) are unable to fulfill basic needs; have potential nutritional deficit, and impose external effect on participants emotional and psychological wellbeing.

Being gossiped (a psychological factor) sometimes and often in the last 12 months of the study period due to the status of HIV positivity were significantly 
associated for suicidal attempt as compared with individuals who didn't witnessed gossip. This finding is in line with studies done in New York City [51]. Using alcohol in the last three months before the study period was significantly associated with suicidal attempt as compared with who did not use. This finding is in agreement with studies done in New York City [51], US cities [46] and Virginia Commonwealth University [48].

Among clinical factors that contributed for suicidal attempt was suffering from depressive and anxiety symptoms. Study subjects who experienced mild and moderate-to-severe depression and anxiety symptoms had higher odds to have suicidal attempt as compared with individuals who had no symptoms. This result is consistent with the finding of the studies done in New York City [20], Virginia Commonwealth University [48], Puerto Rico [52] and semi-urban Uganda [11].

\section{Limitations of the study}

This study uses the most recent CD4 count by reviewing client's chart; and not the actual CD4 count requested during data collection. There would be possibility of recall bias as participants might forget their suicidal experiences long ago in their life.

\section{Conclusion and recommendations}

Prevalence of suicidal ideation and attempt among PLWHA in our selected hospitals were higher compared to previous reports of general population studies in Ethiopia. Low monthly income, living alone, suicidal thought before knowing seropositive status, family history of suicide, experiencing mild and moderate-to-severe depression and anxiety symptoms, being gossiped sometimes in the previous 12 months of the study period due to HIV status and ever use of khat were statistically significant associated factors with suicidal ideation. In addition, low monthly income, experiencing mild and moderateto-severe depression and anxiety symptoms, being gossiped sometimes and often in the previous 12 months of the study period due to HIV status and using alcohol currently were significantly associated factors of suicidal attempt.

The following recommendations are suggested based our findings. It is better for North Shewa zonal health bureau to strengthen and scale up the primary health care (PHC) mental health program_Mental Health Gap Action Programme (mhGAP) which has been already started; and target should include PLWHA. And it is better to collaborate with regional health bureau and other stake holders to equip public hospitals with necessary mental health services and linkage with HIV/AIDS care clinics. In addition, it is better if interdepartmental communication between HIV and psychiatric clinics is initiated and make it functional and sustainable at Debre Berhan Comprehensive Specialized Hospital and another similar setting.

Besides, it is recommended to assess and address the social support system and economical aspect; previous self, or family history of suicidal behavior; concurrent depressive or anxiety symptoms, experience of stigma; and substance use (like khat and alcohol use) for HIV infected individuals.

Lastly, it is advised that future research should focus on recent risk assessment of suicidal behavior and actual committed suicide among PLWHA from HIV/AIDS care centers using more strong study designs (like follow-up study) comprising comparison groups which might help to develop or scale-up appropriate psychosocial support systems and interventions.

\section{Supplementary Information}

The online version contains supplementary material available at https://doi. org/10.1186/s12991-021-00335-5.

Additional file 1. The schematic presentation of sampling procedures among PLWHA at selected hospitals of North Shewa Zone, Amhara region, Ethiopia, 2017.

\section{Abbreviations}

ART: Antiretroviral therapy; ARV: Antiretroviral; BSI: Beck Scale for Suicide Ideation; Cl: Confidence Interval; HAART: Highly active antiretroviral therapy; HIV/AIDS: Human Immune Deficiency Virus/Acquired Immune Deficiency Syndrome; OR: Odds ratio; PLWHA: People living with HIV/AIDS; PRO: Patient reported outcome; SPSS: Statistical Package for Social Science; SSA: SubSaharan Africa; UK: United Kingdom; USA: United States of America; WHO: World Health Organization.

\section{Acknowledgements}

We would like to thank PLWHA for their willingness to participate in the study. Our appreciation is dedicated to DBU for financial support used in data collection and AMARI (African Mental health Research Initiative) which is funded through the DELTAS Africa Initiative (DEL-15-01) for providing training to Kefyalew Dagne Gizachew in skills of statistical analysis and scientific writing of reports and manuscripts.

\section{Authors' contributions}

KDG conceived the idea and selected the title and design, developed the proposal and measurement tools, coordinated for collection of the data, carried out the statistical analysis, and made write-up of the manuscript (corresponding author). ADU did write-up of the final report and revised the manuscript; YAC and EAB participated in the design of the study and data collection; and SAM contributed for interpretation of the data, and substantively revised the manuscript. All authors and agreed to be accountable for all aspects of the research report. All authors read and approved the final manuscript.

\section{Funding}

This study was funded by Debre Berhan University (DBU) for data collection and there was no additional grant support. The views expressed in this publication are those of the author(s) and not necessarily those of DBU, African Academy of Sciences (AAS), New Partnership for Africa's Development Planning and Coordinating Agency (NEPAD Agency), Wellcome Trust or the UK government. 


\section{Availability of data and materials}

All relevant materials and data supporting the findings of this study are contained within the manuscript and relevant document will be available upon request.

\section{Ethics approval and consent to participate}

Ethical clearance was obtained from Debre Berhan University Ethical Review Board (IRB). Data collected for the purpose of this study never contained identifying information rather coded numbers to guarantee confidentiality of participants. Participants were fully informed about the aims and methods of the study prior to starting the interview and informed consent was obtained. Participants were informed to decline at any time if they felt uncomfortable, even after the interview was started.

\section{Consent for publication}

Not applicable.

\section{Competing interests}

The authors declare that they have no competing interests.

\section{Author details}

${ }^{1}$ Department of Psychiatry, College of Health Sciences and Medicine, Debre Berhan University, P.O. Box 445, Debre Berhan, Ethiopia. ${ }^{2}$ Department of Psychiatry, College of Health Sciences, Addis Ababa University, Addis Ababa, Ethiopia. ${ }^{3}$ Department of Psychiatry, College of Health Sciences, Dilla University, Dilla, Ethiopia. ${ }^{4}$ School of Nursing and Midwifery, Department of Pediatric and Child Health Nursing, College of Medicine and Health Sciences, Wollo University, Dessie, Ethiopia.

Received: 20 July 2020 Accepted: 7 February 2021 Published online: 19 February 2021

\section{References}

1. Samra J, Monk L. Working With the Client Who is Suicidal: A Tool for Adult Mental Health and Addiction Services. 2007.

2. Wreen M. The definition of suicide. Soc Theory Practice. 1988;14(1):1-23.

3. Jenkins R, Baingana F, Ahmad R, McDaid D, Atun R. Mental health and the global agenda: core conceptual issues. Mental Health Fam Med. 2011;8(2):69.

4. Alimohammadi A, Mehrpisheh S, Memarian A. Epidemiology of Cases of Suicide due to Hanging who Referred to Forensic Center of Shahriar in 2011. Int J Med Toxicol For Med. 2013;3(4):121-5.

5. Suicide WP. A global Imperative. 2014. http://www.whointgate1 inistfr/ mental health/suicide-prevention/world report_2014/en. 2018.

6. Naghavi M. Global, regional, and national burden of suicide mortality 1990 to 2016: systematic analysis for the Global Burden of Disease Study 2016. BMJ. 2019:364:9.

7. Vijayakumar $\mathrm{L}$, John S, Pirkis J, Whiteford $H$. Suicide in developing countries (2) risk factors. Crisis. 2005;26(3):112-9.

8. Jenkins R, Baingana F, Ahmad R, McDavid D, Atun R. Should low-income countries and other development actors care about mental health. Commonw Health Partnersh. 2013;23:18-25.

9. Lawrence ST, Willig JH, Crane HM, Ye J, Aban I, Lober W, et al. Routine, self-administered, touch-screen, computer-based suicidal ideation assessment linked to automated response team notification in an HIV primary care setting. Clin Infect Dis. 2010;50(8):1165-73.

10. Seeley J. HIV and East Africa: Thirty years in the shadow of an epidemic. New York: Routledge; 2015.

11. Kinyanda E, Hoskins S, Nakku J, Nawaz S, Patel V. The prevalence and characteristics of suicidality in HIV/AIDS as seen in an African population in Entebbe district, Uganda. BMC Psychiatry. 2012;12(1):63.

12. Beckett A, Shenson D. Suicide risk in patients with human immunodeficiency virus infection and acquired immunodeficiency syndrome. Harvard Rev Psychiatry. 1993;1(1):27-35.

13. Douaihy A, Singh N. Factors affecting quality of life in patients with HIV infection. AIDS Reader. 2001;11(9):450-4.

14. Badiee J, Moore DJ, Atkinson JH, Vaida F, Gerard M, Duarte NA, et al. Lifetime suicidal ideation and attempt are common among HIV+ individuals. J Affect Disord. 2012;136(3):993-9.
15. Bellini M, Bruschi C. HIV infection and suicidality. J Affect Disord. 1996:38(2-3):153-64.

16. Siegel $\mathrm{K}$, Meyer $\mathrm{H}$. Hope and resilience in suicide ideation and behavior of gay and bisexual men following notification of HIV infection. AIDS Educ Prev. 1999:11:53-64.

17. Marzuk PM, Tierney H, Tardiff K, Gross EM, Morgan EB, Hsu M-A, et al. Increased risk of suicide in persons with AIDS. JAMA. 1988;259(9):1333-7.

18. Coté TR, Biggar RJ, Dannenberg AL. Risk of suicide among persons with AIDS: a national assessment. JAMA. 1992;268(15):2066-8.

19. Keiser O, Spoerri A, Brinkhof MW, Hasse B, Gayet-Ageron A, Tissot F, et al. Suicide in HIV-infected individuals and the general population in Switzerland, 1988-2008. Am J Psychiatry. 2010;167(2):143-50.

20. "Suicidality and Violence in Patients With HIV/AIDS - TheBodyPro." 2006, https://www.thebodypro.com/article/suicidality-violence-patients-hivaids. Accessed 27 Nov. 2020.

21. Dannenberg AL, MCNeil JG, Brundage JF, Brookmeyer R. Suicide and HIV infection: mortality follow-up of 4147 HIV-seropositive military service applicants. JAMA. 1996;276(21):1743-6.

22. Sherr L, Lampe F, Fisher M, Arthur G, Anderson J, Zetler S, et al. Suicidal ideation in UK HIV clinic attenders. Aids. 2008;22(13):1651-8.

23. Shibre T, Hanlon C, Medhin G, Alem A, Kebede D, Teferra S, et al. Suicide and suicide attempts in people with severe mental disorders in Butajira, Ethiopia: 10 year follow-up of a population-based cohort. BMC psychiatry. 2014;14(1):1-12.

24. Mekonnen D, Kebede Y. The prevalence of suicidal ideation and attempts among individuals attending an adult psychiatry out-patient clinic in Gondar, Ethiopia. Afr Health Sci. 2011;11:1

25. Alem A, Kebede D, Jacobsson L, Kullgren G. Suicide attempts among adults in Butajira. Ethiopia Acta Psychiatrica Scandinavica. 1999;100:70-6.

26. Kebede D, Alem A. Suicide attempts and ideation among adults in Addis Ababa. Ethiopia Acta Psychiatrica Scandinavica. 1999:100:35-9.

27. Mekonen T, Getnet A, Belete A, Menberu M, Fekadu W. Suicidal behavior among people with epilepsy in Northwest Ethiopia: A comparative crosssectional study. Epilepsy Behav. 2020;111:107233.

28. Gebremariam EH, Reta MM, Nasir Z, Amdie FZ. Prevalence and associated factors of suicidal ideation and attempt among people living with HIV/ AIDS at Zewditu Memorial Hospital, Addis Ababa, Ethiopia: a cross-sectional study. Psychiatry J. 2017;2017:9.

29. Bitew H, Andargie G, Tadesse A, Belete A, Fekadu W, Mekonen T. Suicida ideation, attempt, and determining factors among HIV/AIDS patients. Ethiopia Depression Res Treatment. 2016;2016:8.

30. Kindaya GG, Demoze CK. Lifetime Prevalence and Determinants of Suicidal Ideation and Attempt Among All Patients Living with HIV/AIDS in Hiwot Fana Specialized Hospital, Harar, Ethiopia, 2020. HIV/AIDS (Auckland, NZ). 2020;12:331.

31. O'Connor E, Gaynes B, Burda BU, Williams C, Whitlock EP. Screening for suicide risk in primary care: a systematic evidence review for the US Preventive Services Task Force.

32. Catalan J, Harding R, Sibley E, Clucas C, Croome N, Sherr L. HIV infection and mental health: suicidal behaviour-systematic review. Psychol Health Med. 2011;16(5):588-611.

33. Stang I A, Brady B, Fritz K. Technical brief: measuring HIV stigma and discrimination. Washington, DC: International Center for Research on Women; 2012.

34. Organization WH. Composite international diagnostic interview (CIDI), version 1.1. Composite International Diagnostic Interview (CIDI), Version 111993.

35. Rashid E, Kebede D, Alem A. Evaluation of an Amharic version of the composite international diagnostic interview (CIDI) in Ethiopia. Ethiop J Health Development (EJHD). 1996;10:2.

36. Group WAW. The alcohol, smoking and substance involvement screening test (ASSIST): development, reliability and feasibility. Addiction. 2002;97(9):1183-94

37. Humeniuk R, Ali R, Babor TF, Farrell M, Formigoni ML, Jittiwutikarn J, et al. Validation of the alcohol, smoking and substance involvement screening test (ASSIST). Addiction. 2008;103(6):1039-47.

38. Kroenke K, Spitzer RL, Williams JB, Löwe B. An ultra-brief screening scale for anxiety and depression: the PHQ-4. Psychosomatics. 2009;50(6):613-21.

39. Kroenke K, Spitzer RL, Williams JB. The Patient Health Questionnaire-2: validity of a two-item depression screener. Med Care. 2003;8:1284-92. 
40. Kroenke K, Spitzer RL, Williams JB, Monahan PO, Löwe B. Anxiety disorders in primary care: prevalence, impairment, comorbidity, and detection. Ann Intern Med. 2007;146(5):317-25.

41. Dalgard OS, Dowrick C, Lehtinen V, Vazquez-Barquero JL, Casey P, Wilkinson $\mathrm{G}$, et al. Negative life events, social support and gender difference in depression. Soc Psychiatry Psychiatr Epidemiol. 2006;41(6):444-51.

42. Dalgard O. Community health profile as tool for psychiatric prevention. Promotion of Mental Health. 1996;5:681-95.

43. Borneman T, Ferrell B, Puchalski CM. Evaluation of the FICA tool for spiritual assessment. J Pain Symptom Manage. 2010;40(2):163-73.

44. Soeken KL, McFarlane J, Parker B, Lominack MC. The Abuse Assessment Screen: a clinical instrument to measure frequency, severity, and perpetrator of abuse against women. 1998.

45. Martikainen P, Aromaa A, Heliövaara M, Klaukka T, Knekt P, Maatela J, et al. Reliability of perceived health by sex and age. Soc Sci Med. 1999:48(8):1117-22

46. Carrico AW, Johnson MO, Morin SF, Remien RH, Charlebois ED, Steward WT, et al. Correlates of suicidal ideation among HIV-positive persons. Aids. 2007;21(9):1199-203.

47. Govender R, Schlebusch L. Suicidal ideation in seropositive patients seen at a South African HIV voluntary counselling and testing clinic. African Journal of Psychiatry. 2012;15(2):94-8.

48. Haller DL, Miles DR. Suicidal ideation among psychiatric patients with HIV: psychiatric morbidity and quality of life. AIDS Behav. 2003;7(2):101-8.
49. Shelton AJ, Atkinson J, Risser JM, McCurdy S, Useche B, Padgett P. The prevalence of suicidal behaviours in a group of HIV-positive men. AIDS care. 2006;18(6):574-6.

50. Chikezie U, Otakpor A, Kuteyi O, James B. Suicidality among individuals with HIV/AIDS in Benin City, Nigeria: a case-control study. AIDS care 2012;24(7):843-5.

51. Vance DE, Moneyham L, Fordham P, Struzick TC. A model of suicidal ideation in adults aging with HIV. J Assoc Nurses AIDS Care. 2008;19(5):375-84.

52. Quintana-Ortiz RA, Gomez MA, Baez Feliciano D, Hunter-Mellado RF. Suicide attempts among Puerto Rican men and women with HIV/AIDS: a study of prevalence and risk factors. Ethnicity \& disease. 2008;18(2 supplement 2):S2-219.

53. Yuh JN, Ellwanger K, Potts L, Ssenyonga J. Stigma among HIV/AIDS patients in Africa: a critical review. Procedia-Social and Behavioral Sciences. 2014;140:581-5.

54. Cooperman NA, Simoni JM. Suicidal ideation and attempted suicide among women living with HIV/AIDS. J Behav Med. 2005;28(2):149-56.

\section{Publisher's Note}

Springer Nature remains neutral with regard to jurisdictional claims in published maps and institutional affiliations.
Ready to submit your research? Choose BMC and benefit from:

- fast, convenient online submission

- thorough peer review by experienced researchers in your field

- rapid publication on acceptance

- support for research data, including large and complex data types

- gold Open Access which fosters wider collaboration and increased citations

- maximum visibility for your research: over $100 \mathrm{M}$ website views per year

At $\mathrm{BMC}$, research is always in progress.

Learn more biomedcentral.com/submissions 